\begin{tabular}{|c|c|c|}
\hline $\begin{array}{l}\text { Editorial \& Publishing Offices : } \\
\text { Macmillan \& Co., LTD. } \\
\text { ST. MARTIN's STREET } \\
\text { LONDON, W.C.2 }\end{array}$ & 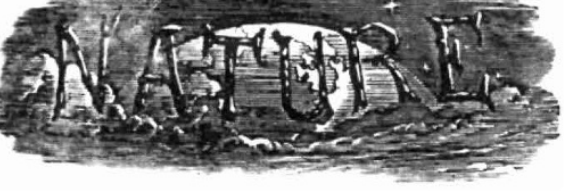 & $\begin{array}{l}\text { Telegraphic Address : } \\
\text { Phusis, Lesquare, LoNDoN } \\
\text { Telephone Number: } \\
\text { WhrteHALI } 88_{31} \text {. }\end{array}$ \\
\hline Vol. 147 & SATURDAY, JANUARY I8, I94I & No. 3716 \\
\hline
\end{tabular}

\title{
UTILIZATION OF MAN POWER
}

$\mathrm{T}$

HE new appeal for volunteers for training for war work and the emphasis placed on the need for the employment and training of women show that the magnitude of the man-power question is now at last being recognized. Mr. Bevin has indeed, during the time in which he has exercised his immense powers of control over labour and industry, been fully alive to the importance of the human factor. He cannot be accused of being unmindful of the findings of the Industrial Health Research Board, and the stress he has laid in various speeches on the provision of canteens, communal feeding, and the safeguarding of health have indicated his profound concern with the maintenance of morale and health. There is, indeed, no room whatever for doubts as to the Minister of Labour and National Service holding a long-term view of industrial efficiency, and as to his determination to allow no shortsighted views of output and hours of work to impair the physical, mental and moral capacities of the workers on whose endurance, skill and enthusiasm we depend for long-sustained production.

Such uneasiness as may exist in regard to the man-power position and its handling arises largely from the same type of considerations as have led to criticisms of the scope and functions of the new Ministry of Works and Buildings. It is a question of the co-ordination and direction of our war-effort to the maximum efficiency. It is to be hoped that the new executive committee of Cabinet Ministers announced on January 6 will secure a measure of the co-operation which is imperative.

Examples of this lack of co-ordination are easily found. The Limitation of Supplies Order is part of a consistent policy of the Board of Trade to cut down severely the volume of manufacture for the home market. The aim of this policy is not merely the restriction of spending by the general public, but also, and equally important, the reduction of effort in non-essential industries. Similarly, the change of export policy from one of indiscriminate encouragement of all exports to one of selective encouragement is bound to result in displacement of labour in the manufacturing industries, distribution and perhaps especially among the retail shopkeepers.

In theory, the labour thus displaced is available for, and should be taken up by, the munitions industries. In practice, despite the somewhat misleading figures issued by the Ministry of Labour, it is not being taken up, or at least absorbed, with the completeness and rapidity that are desirable. There is little evidence of effort specifically designed to assist the transition by training in advance.

The failure of the Board of Trade and Ministry of Labour to dovetail is the more serious in view of the strain which sustained air attack places on the civil population. Consideration of the welfare side of the transition of labour, educational work designed to prepare men and women for change, to free them from unnecessary hardship or anxiety, is just as important a factor in the smooth supply of the million more workers required by next August for the armaments plan of the Ministry of Labour as it is in the handling of the dilution problem and the training of fresh labour in the shops, both as regards employers and individual workers. The Government is perhaps awaiting the results of the survey on which Sir William Beveridge is engaged, before committing 
itself to a more definite policy. It is time more was heard about this survey.

The million workers required can only be obtained by ruthlessly squeezing labour out of the non-essential industries, and there is little evidence that the reduction of the personnel of the nonessential industries is being carried through in anything but the most haphazard way. The Government has been silent, too, about the pooling of enterprises, or about compensation for works closed down-factors which also affect morale. There is no indication of prompt and firm administrative action to prevent wastage among labour evacuated from the coasts, or among that, often highly skilled, temporarily displaced by air-raid attacks.

The simultaneous immensely larger demands of the fighting services for men, who will have to be provided from the same source and even from among present war workers, makes the ruthless elimination of waste of man-power of the utmost importance. Civil defence workers provide a further complication. The balance between the different branches of civil defence-fire services, first aid, rescue and demolition services-requires reconsideration in the light of experience of recent months. Moreover, the most effective use of the minimum number of full-time workers consistent with safety cannot be secured without efficient organization of the much larger body of part-time workers, whose morale and efficiency, it should be remembered, are determined both by that of the community in which they live and of the industry in which they are engaged. Much more might be done to ensure the rational use of such part-time services in ways which would foster their keenness and loyalty without putting intolerable strain on their health or devotion.

Such organization of civil defence services, including the provision of reasonable amenities during the additional strain which weather and darkness impose during the winter months, is an essential part of the efficient use of our man-power resources. The wise use of military resources in the more technical tasks of clearance and repair to reinforce labour already available is an example of the type of elasticity and co-ordination required.

As already suggested, much more might be done to minimize the stress and strain of the vast change-over required. Most important at the present moment, however, is the problem of thelargescale training of men and women whose normal jobs have come to an end. Moreover, something in the nature of a system of priorities may be demanded in regard to man-power as well as supplies.

What must be realized is that the new demands involve a profound disturbance, not merely of our standards of living, but also of our domestio life. The great army of women workers required for our munition factories will not be recruited without grave social problems being encountered, both within industry and without. The reactions on the supply of helpers for many of the voluntary services of all kinds may be seriously adverse.

The importance of the proper distribution of skilled labour is not yet sufficiently recognized. Until it is distributed among the thousands of firms in the manner best suited to the mass production of munitions, we shall not achieve our maximum production, nor indeed be able to utilize effectively in the less skilled jobs our full resources of man- or woman-power. Skilled labour of any kind must in fact be regarded as first the possession of the State, rather than of any individual firm.

Recognition of key workers, especially tool-room workers and machine-setters, as a sort of national pool must be followed by proposals to make such a declaration more effective in the day-to-day hiring and employment of such industrial craftsmen. Further, this is true also of the training of the rank and file of fresh workers to do the less skilled jobs. These men and women are being trained to enter industry at whatever point their services may be needed, and the particular em. ployer of any trainee is no more than the agent of the Government, upon whose production programme the scale and incidence of these extra labour requirements directly depend.

Mr. Bevin's references to the importance of psychological factors as a justification for not resorting to compulsion may in theory be sound enough. But there must be no squeamishness in dealing with anything allied to obstructive tendencies. There are already indications of undue deference, if not subservience, to vested interests in various fields, including that of food policy and agriculture, which endanger the high mood in which the nation faced the perils of early summer.

The need for wise planning and central direction of our man-power policy is cardinal, but the central machinery and plan must function smoothly. Just as the National Register can only be used to complete or perfect the main process of transfer or adjustment initiated in other ways, so the 
increasing attention to the safety of workers in factories, the improvement of amenities, the provision of canteens, the placing of workers to eliminate unnecessary travelling, and the avoidance of excessive hours of work, are designed essentially to ensure that man-hours vital to output are not lost by allowing conditions to arise that impair health and efficiency.

As already emphasized, such factors have to be considered in relation to the conditions of the civil population as a whole. Billeting and dispersal plans prepared to facilitate uninterrupted industrial production cannot be considered apart from arrangements made in regard to the evacuation of school children or other special classes of the community. Education itself must be considered in reference to the morale of the adolescent population and the future supply of juvenile workers throughout the national life. Moreover, there is still evidence of failure to make full use of the available services of special types of worker; as, for example, of biologists, or of various classes of friendly aliens at present interned, though the recent orders for registration of the latter for employment is a step in the right direction.

The seriousness of the challenge which is now thrown down to us by night-bombing and by the attacks on our shipping must not be mistaken. No prejudices must stand in the way of the gigantic effort demanded of us. However severe those demands, or drastic the sacrifices they may involve of ways of living and freedom, it is certain that if they are presented with imagination and understanding, they will evoke as great a response as the disasters and perils through which we have already passed.

\section{PHYSICS IN MODERN LIFE}

\section{Physical Science in Art and Industry}

By Dr. E. G. Richardson. Pp. xi $+293+6$ plates. (London: English Universities Press, Ltd., 1940.) 15s. net.

IN a specialist age such as the present, there 1 must be a grievous loss of that legitimate pleasure which derives from the possession of knowledge over a wide field of human endeavour. Again, it is clear that much needless duplication of effort is continually going on, because people wholly absorbed in prosecuting one particular quest (probably with great zeal and application) are partly or wholly ignorant of what others are doing in another sphere, and whose methods might readily be adapted with very little trouble. There seems to be no ready-made cure for this state of affairs. Experience shows that even the most watertight and elaborate system of cross-references to cognate subjects fails to inspire us with a keen desire to look over the wall into our neighbour's garden.

Dr. Richardson, however, is a missionary. $\mathrm{He}$ has taken upon himself the task of discussing anything and everything - so far as the compass of his book permits-which physics can do in modern life. A random glance at the index produced such entries as 'cotton', 'decibels' and 'tilth'; from such an assortment, the scope of the volume can be envisaged. The author's style is easy, even perhaps colloquial here and there, and certainly the reader will have few dull moments, as he is swept along with an enthusiasm almost contagious.

The physics of locomotion occupy three chapters : these are followed by others dealing with communication, pottery, cooking, the farm, hydrology, mining, fine art and archæology, building materials, architecture, music, textiles and war. (It is a relief that the last-named is quite short, and that there is no inclination for its subject-matter to seep through into the rest of the book.)

Naturally, a work such as this offers unrivalled opportunities for any reviewer to dwell upon omissions, and some readers, too, will find their pet notions unrecorded; nevertheless, it is astonishing how complete and coherent the treatment is, and this without any obvious tendency to 'write round the references'.

To make a few specific comments: the section on aeroplanes contains an excellent description of the theory of similitude - and its relation to models -without the introduction of mathematical machinery. This is an example of the way in which Dr. Richardson will probably succeed in helping people to realize that there is such a subject, and that having done that, there is a fair chance that they may discipline themselves to appreciate its beauty when handled analytically.

The development of the locomotive is well brought out. A point which might have been worth making here is that the remarkable capacity for speed shown by engines of recent types (even with coupled wheels of relatively small diameter) is due almost entirely to radical improvements in 'front-end' design, and the study of the flowing properties of highly superheated steam. The 